\title{
COVID-19 and smoking habits: a smoky situation!
}

\author{
Angelo Di Vincenzo, Roberto Vettor, Marco Rossato \\ Clinica Medica 3, Department of Medicine (DIMED), University-Hospital of Padua, Italy
}

\section{Dear Editor,}

the issues recently raised by Carratù et al. [1] on the role of smoking/former smoking in patients hospitalized for COVID-19 all around the world as widely reported in many different published papers, are important for different reasons, although the authors probably did not focus the core of the problem. We completely agree that in COVID-19 patients a careful assessment of smoking history should be mandatory, although it is frequently lacking in the evaluation of COVID-19 patients with severe ARDS. An accurate clinical history is important to precisely classify these patients when analyzing the possible risk or (putatively) protective factors for COVID-19. To this regard it has been reported an unexpectedly low prevalence of current smokers among hospitalized patients with COVID-19 [2,3]. The low prevalence of active smokers among COVID-19 hospitalized patients is confirmed by the low prevalence of COPD in these patients, as reported in many different published papers as recently reviewed by Singh et al. [4]. These observations are not in contrast with the findings that smokers and COPD patients might have more severe COVID-19, although a recent meta-analysis, performed after a sensitivity analysis to exclude heterogeneous case histories, showed that the effects of smoking on the severity of COVID-19 was not significant [5]. Interestingly the only confounding case history of patients was that of Guan et al., which data have been considered

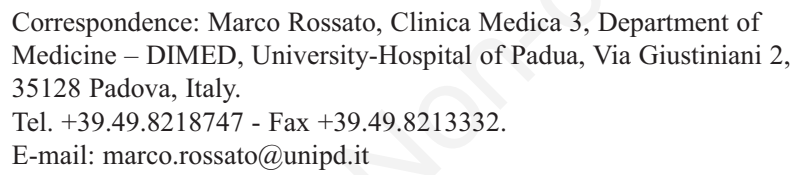

Authors' contributions: All Authors have participated to the discussion of the letter published by Carratù $e t a l$. and to the writing of the present reply.

Conflict of interest: The Authors declare no conflict of interest.

Received for publication: 31 July 2020.

Accepted for publication: 14 September 2020.

${ }^{\circ}$ Copyright: the Author(s), 2020

Licensee PAGEPress, Italy

Monaldi Archives for Chest Disease 2020; 90:1539

doi: 10.4081/monaldi.2020.1539

This article is distributed under the terms of the Creative Commons Attribution Noncommercial License (by-nc 4.0) which permits any noncommercial use, distribution, and reproduction in any medium, provided the original author(s) and source are credited. in the study by Carratù et al. [1]. It is well known that smoking is the main risk factor for COPD and consequently, we would have expected higher prevalence of smokers (and of COPD) in COVID-19 patients, while the contrary has been reported [2-5].

What is important to note is that the rates of active smokers among COVID-19 patients are low in all published studies, with respect to former and no smokers, while one should have expected the opposite. Thus we do not agree with the suggestion of Carratù et al. to group active smokers together with former smokers since it is possible that an important issue could be the presence of smoke (active smokers) with respect to the absence of smoke (former/never smokers). Further studies will be necessary to investigate if this hypothesis is true and its potential pathophysiological mechanisms [6].

\section{References}

1. Carratù P, Boffi R, Dragonieri S. et al. Covid-19 and ex-smokers: an underestimated prognostic factor? Monaldi Arch Chest Dis 2020;90:1463. doi: 10.4081/monaldi.2020.1463

2. Rossato M, Russo L, Mazzocut S, et al. Current smoking is not associated with COVID-19. Eur Respir J. 2020;55: 2001290. doi:10.1183/13993003.01290-2020

3. Farsalinos K, Barbouni A, Poulas K, et al. Current smoking, former smoking, and adverse outcome among hospitalized COVID-19 patients: a systematic review and meta-analysis. Ther Adv Chronic Dis 2020. doi:10.1177/2040622320935765

4. Singh AK, Gillies CL, Singh R, et al. Prevalence of co-morbidities and their association with mortality in patients with COVID-19: A systematic review and meta-analysis. Diabetes Obes Metab 2020. doi:10.1111/dom.14124

5. Zhao Q, Meng M, Kumar R, et al. The impact of COPD and smoking history on the severity of COVID-19: A systemic review and meta-analysis. J Med Virol 2020. doi:10.1002/ jmv.25889

6. Farsalinos K, Niaura R, Le Houezec J, et al. Nicotine and SARS-CoV-2: COVID-19 may be a disease of the nicotinic cholinergic system. Toxicol Rep 2020;7:658-663. doi: 10.1016/ j.toxrep.2020.04.012 